\title{
Preface of the Guest Editor
}

\section{Bruno Hribernik}

MD ASMET Research GmbH, Leoben, Austria

Published online November 6, 2017

ASMET was pleased to welcome 1100 participants to the 3rd ESTAD European Steel Technology Days in Vienna, June 26-19, 2017.

In order to maintain the leading European technical conference for the steel industry, ASMET, AIM, A3M, Steel Institute VDEh, and Jernkontoret organized the 3rd European Steel Technology \& Application Days (ESTAD), 2017.

This event offered the opportunity to get information about the most recent developments of steelmaking processes and steel products.

The international conference focussed on the latest trends and issues and provided a wide networking and information platform for equipment and service suppliers, plant manufacturers and steelmakers.

At this event, the participants acquired the latest information on new ideas and developments as well as on the state-of-the-art in metallurgical process technologies for iron and steel production, steel materials, and steel application.

The presentations focussed on all technical aspects in the main fields of:

- Ironmaking

- Steelmaking

- Rolling

- Steel materials and their application, surface technologies

- Environmental and energy

A technical exhibition was held during the event for equipment and service suppliers, steelmakers and the media. 30 companies took the opportunity to reinforce their participation and enhance their corporate identification by taking advantage of the benefits offered to them as sponsors of the event.

The scientific program included plenary, invited, and contributed lectures from world-leading international scientists from universities and industry.

B. Hribernik $(\square)$

MD ASMET Research GmbH

8700 Leoben, Austria

bruno.hribernik@asmet.at
The authors who contributed to the proceedings of the conference are gratefully acknowledged. The book of proceedings can be ordered from the secretary of ASMET, Yvonne Dworak (yvonne.dworak@asmet.at).

Among the plenary contributions, five papers have been selected for publication in this issue of the BHM:

- Wolfgang Eder: Environment-Climate-Energy: Quo Vadis Industry?

- Franz Rotter und Michael Eder: Digitalisierung in der voestalpine High Performance Metals Division-Evolutionär und Revolutionär

- Andreas Flick, Kurt Herzog, Günther Winter, Gerhard Kurka, Kai Ankermann, Raffael Binder, Markus Ringhofer, Andreas Maierhofer: The Digitalization of Steel Production

- Reinhold Steiner, Gregor Lammer, Christian Spiel, Christoph Jandl: Refractories 4.0

- Hans Jürgen Kerkhoff: Political Conditions for Sustainable Innovations

Special thanks to the members of the scientific committee who reviewed the papers and the chairmen of ESTAD 2017. The successful realization of the conference would not have been possible without their help.

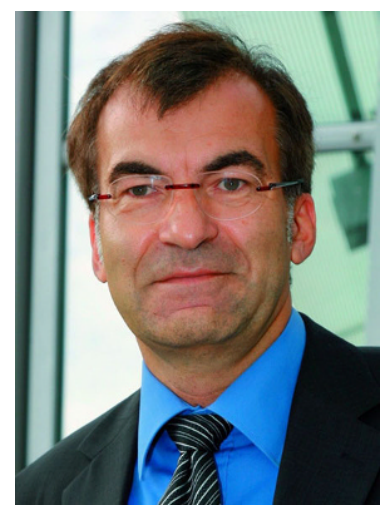

Bruno Hribernik 